\title{
Ambigüedad Organizacional de la Planeación Estratégica. El Caso de la Universidad Autónoma de Sinaloa, región centro-norte
}

\author{
Ambiguity Organizational Strategic Planning. The case of the Autonomous \\ University of Sinaloa north central region
}

\author{
José Guadalupe Vargas Hernández' y José de Jesús López López² \\ ' Centro Universitario de Ciencias Económico Administrativas. Universidad de Guadalajara. México Periférico Norte 799, \\ Edifico G-306, Los Belenes, Zapopan, 45 I00, Jalisco, México \\ 2 Universidad Autónoma de Sinaloa, Guasave. \\ jvargas2006@gmail.com
}

Fecha de recepción: 22-04-2010

Fecha de aceptación: 19-08-2010

\begin{abstract}
Resumen: Este trabajo tiene por objetivo determinar el grado de influencia de la planeación estratégica en el combate a la ambigüedad organizacional en la Universidad Autónoma de Sinaloa en su región Centro-Norte. La investigación es experimental y aplica la escala de Likert como instrumento de campo. Entre los hallazgos importantes, esta investigación encuentra que la organización tiene que buscar acoplar firmemente los objetivos e intereses de sus participantes para encontrar respuestas más completas en la planeación estratégica, que requiere mayor racionalidad, pero en las condiciones descritas, ésta encuentra grandes limitaciones, es decir, cada vez puede estar más lejos de cumplirse el objetivo con las acciones tomadas, ya que el camino seguido para hacer esto, no es claro.
\end{abstract}

Palabras clave: Ambigüedad, organización, planeación estratégica, racionalidad limitada.

Abstract: This paper has the aim to determine the degree of influence of strategic planning in combating organizational ambiguity in the Autonomous University of Sinaloa in the north central region. The research is experimental and applies the Likert scale as field instrument. Among the important findings, this research finds that the organization must seek to achieve the objectives and interests of its participants to find answers more complete in strategic planning, which requires greater rationality, but in the described circumstances, it faces important limitations, this means it can be further away from meeting the goal with the actions taken, since the path followed to do so, is unclear.

Keywords: Ambiguity, organization, strategic planning, bounded rationality.

\section{Introducción: antecedentes del problema}

Las universidades han experimentado una de las transformaciones más significativas de su historia. Los cambios operados en estos años han impactado como nunca antes, prácticas y formas de organización y gobierno de cada universidad, modificando con ello, de manera sustancial, su significado como institución social. La Universidad fue por mucho tiempo una institución cerrada, volcada en sí misma y para sí misma, entregada en su encierro a cultivar saberes que posibilitarían sus depositarios una mayor movilidad social, y a funcionar como válvula de escape de las presiones políticas de un régimen autoritario.
El comportamiento de la organización en el caso de la UAS, en la década de los 50's y 60's, funciona con una administración flexible al máximo para atender el llamado popular y democrático de su origen durante los movimientos sociales de ese tiempo. En la actualidad se presenta la necesidad de reforma en todos los órdenes, llevando a la institución a tomar en cuenta los proyectos globales de educación, al tiempo en que conserva parte de su comportamiento organizacional. Ante tales contextos, las exigencias actuales no pueden arrojar resultados positivos inmediatos.

Se adopta como práctica habitual la planificación estratégica para identificar sus actividades, generar y 
articular su visión estratégica y desarrollar tareas básicas de la administración y gestión de recursos (Albors-Garrigós, del Val Segarra, y Rincón-Díaz, 20 l0). La planeación estratégica se aplica actualmente en la Universidad Autónoma de Sinaloa, iniciando con esta metodología desde el año 200 I dentro de lo que se llama, Plan Águila de Desarrollo Institucional (200 I-2005). Este sistema contempla tanto las áreas académicas como las administrativas y contiene la información relacionada con los procesos administrativos, financieros, el control escolar y el manejo de los recursos humanos de la Institución. Este sistema se perfila como un modelo conceptual a integrar en una red estatal universitaria de escuelas y facultades; así como todos los niveles que la institución ofrece, en los 18 municipios del Estado, en las cuatro zonas geográficas en que se divide.

Se ha estado avanzando en procesos administrativos con la aplicación de la Planeación Estratégica, planteando los estándares generales de las instituciones de Educación Superior, pero hay lentitud en el cumplimiento de sus compromisos del entorno, ante una sociedad cada vez más exigente. Existe un ambiente de transición exigido por entes y elementos internos y externos, ante los cuales se trabaja bajo la presión de los resultados, asignación de recursos de acuerdo al rendimiento, donde las instituciones de educación superior, presentan la necesidad de ajustar su organización.

\section{Objetivos e hipótesis}

Este trabajo tiene por objetivo general determinar la relación de la Planeación Estratégica, en el combate a la ambigüedad organizacional actual en la Universidad Autónoma de Sinaloa, unidad Centro-Norte y prescribir los factores adversos.

Los objetivos específicos son:

A) Determinar la influencia de la planeación estratégica en el mejoramiento de las relaciones colectivas, de poder y cooperación y plantear estrategias correctivas.

B) Analizar los resultados de la planeación estratégica en la racionalidad de objetivos y su relación con los objetivos individuales de los participantes en la organización.

C) Determinar la relación de la planeación estratégica en la adecuación de los recursos financieros y en los incentivos a los participantes de la organización.
A partir de los objetivos anteriores se establecen las hipótesis

\section{Hipótesis general}

Los altos niveles de ambigüedad organizacional que padece la Universidad Autónoma de Sinaloa actualmente, serán reducidos con la correcta aplicación de la planeación estratégica.

\section{Hipótesis particulares}

A) La orientación hacia el equilibrio de conflictos en las relaciones colectivas de poder y cooperación en la Universidad Autónoma de Sinaloa, no encuentra respuestas suficientes en la planeación estratégica, dadas las ambigüedades de la toma de decisiones frente a los viejos problemas de integración de la organización, lo cual, requiere de la integración entre organización e individuo.

B) La racionalidad en las decisiones, hacia la concreción de los resultados planeados, se complica en la contradicción de objetivos de la organización frente a objetivos individuales de los participantes.

C) La planeación estratégica tiene una alta funcionalidad en la racionalización de los recursos, en la Universidad; es necesario el estímulo eficiente a la participación en tareas y gasto canalizado hacia objetivos estratégicos, lo cual llevará a la cabalidad la reducción en la confusión de objetivos y acciones.

\section{Condiciones administrativas en la Región Centro-Norte de la UAS}

La Coordinación Centro-Norte de la Universidad Autónoma de Sinaloa se encuentra comprendida en las localidades de Guamúchil, Angostura, Mocorito, Sinaloa y Guasave. La Universidad Autónoma de Sinaloa participa en esta región, primero con educación de bachillerato, con centros en Guasave, Guamúchil, Mocorito y la Reforma en orden de fundación. Estas escuelas que encontraron su desarrollo y estabilidad en la amplia demanda de la región, por la educación de bajo costo, posibilidad que la UAS brindó desde su fundación, dado el carácter con que surgió. La demanda creciente en términos de matricula llevó a la fundación de otros centros formados como extensiones de estas escuelas, tal es el caso de cada uno 
de los ya mencionadas, sobresaliendo la preparatoria Guasave Diurna, en ese sentido con varias extensiones de grupos desplazados.

La actividad educativa se encuentra administrada con una coordinación general, coordinación académica y una coordinación administrativa. Además de la sub coordinación regional en Guasave con sus respectivas áreas de sub coordinación académica y administrativas, además de la coordinación de servicios asistenciales. De acuerdo a datos de tesis de López López, (2004:6I), la actividad académica está distribuida en 16 escuelas, de las cuales, tres son del nivel superior y dos centros de idiomas; I I son del nivel bachillerato, considerando cinco de ellas como escuelas y el resto (seis de ellas), como extensiones. En estos 16 centros de trabajo, se tienen 56 trabajadores en lo que corresponde a actividades directamente administrativas, contando en ellos a los directores de escuela. Sumados los siete elementos de la coordinación y la sub coordinación regional, son 63 los elementos administrativos de la región Centro-Norte.

La Coordinación Centro-Norte de la Universidad Autónoma de Sinaloa, ha estado abordando la obligatoriedad de los procesos de reforma académica y administrativa, pero tal proceso no puede evitar el comportamiento y sus relaciones. Tal es el caso de sus conflictos en las relaciones de poder y sus problemas administrativos. Los participantes en esta, pueden negociar para equilibrar la toma de decisiones, pero pronto se termina esa disposición debido a decisiones e intereses personales, así que se tiene que estar buscando esa disposición continuamente, esto tiene que ver con que las coordinaciones regionales funcionan con flexibilidad con respeto a las actividades centrales. La falta de cohesión entre los miembros de la institución, hace que las coordinaciones regionales, en lugar de funcionar como delegaciones de responsabilidad, se impulsen más la heterogeneidad, como sucede en esta región con la competencia entre grupos de trabajo, en constante enfrentamiento en las relaciones de poder.

\section{Modelo de planeación estratégica en la Universidad Autónoma de Sinaloa}

En la elaboración de los planes estratégicos se busca la participación del mayor número de personas que forman parte de las dependencias de educación superior e instancias administrativas en el proceso de construcción de soluciones y definición de acciones, lo que genera el compromiso necesario, asegurando la transferencia a la realidad de las soluciones planteadas por los grupos. La planeación estratégica incluye una revisión de la misión y metas de la organización, sus fortalezas, debilidades, oportunidades y amenazas. La planeación estratégica está enfocada al logro de los objetivos institucionales y tiene como finalidad básica el establecimiento de guías generales de acción de la misma (UAS; 2002:2). Este tipo de planeación se concibe como el proceso que consiste en decidir sobre los objetivos de una organización, sobre los recursos que serán utilizados, y las políticas generales que orientaran la adquisición y administración de tales recursos, considerando a la institución como una entidad total.

En cuanto a la ambigüedad en procesos administrativos en la UAS, de acuerdo a resultados de tesis (López López, 2004: I 5), observa que las consideraciones del problema de ambigüedad en el proceso administrativo de la UAS son en varios sentidos: de manera visible en la toma de decisiones hay carencia de sencillez, medición y racionalidad, lo cual se presenta con la falta de comunicación de los espacios administrativos centrales hacia los descentralizados (escuelas y otros centros de actividad). La unidad Centro-Norte, enfrenta el carácter de ambigüedad en varios sentidos: La confusión o subjetividad en la intención está dada en que existen objetivos y programas globales en la institución, pero la ejecución por parte de cada sub órgano no es clara. El criterio ambiguo facilita su incumplimiento (Chivite, S y Monroy, C. R., 2009). Por otro lado, es importante tener instrucciones precisas y no ambiguas que puedan ser posteriormente utilizadas en el desarrollo del sistema (Cuenca, LI., Boza, A., Alarcón, F, y Lario, F.C., 2009). De este modo, la coordinación aparece como duplicidad de funciones administrativas porque no sobresale con la parte activa que le corresponde, lo cual genera mayor centralismo.

Otro de los elementos de confusión en el proceso modernizador con ambigüedad es que si se están atendiendo los programas nacionales, donde la UAS participa como una Universidad en proceso de actualización de dicha dinámica, pero falta certeza, sobre todo en las coordinaciones regionales como la zona en cuestión, en cuanto al éxito o fracaso de tales aplicaciones; así que se siguen las reglas debido a la obligatoriedad en indicaciones de los organismos centrales de educación, como la Secretaria de Educación Pública. En esta región de la Universidad estudiada, el concepto de anarquía organizada es tomado en cuenta, debido a los aspectos de ambigüedad ya planteados, pero además, algo muy importante, es el papel que deben jugar los funcionarios y coordinador de la unidad, ya que no hay claridad en el tipo de 
decisiones que les corresponde ejercer y las que deben tomarse por la administración central. Aunado a tal confusión, se presenta una variedad de distintos participantes en el proceso decisorio.

\section{Planeación estratégica, incertidumbre, ambigüedad organizacional y contradicción de objetivos}

De acuerdo a consideraciones de Gallardo y Sánchez (1995), el proceso de planeación, es un procedimiento formal para generar resultados articulados en la forma de un sistema integrado; es la descomposición de un proceso en pasos claros y articulados, asociado a un proceso racional. En otras palabras, a pesar de lo que se diga en contra, la planeación en lo general y más específicamente la planeación estratégica, no significa pensar estratégicamente, sino pensar en forma racionalizada, descompuesta y articulada respecto de las estrategias a implementar.

Consideran Kets y Miller (citados por Gallardo y Sánchez, 1995), que la obsesión por el control refleja a tal grado el miedo a la incertidumbre. Una cultura con bajo nivel de evitamiento de incertidumbre, acepta la ambigüedad como parte inherente a los retos que ofrecen los empleos para el desarrollo individual; mientras que una cultura con alto nivel de evitamiento de incertidumbre, los empleados tratan de evitar actividades que le signifique niveles altos de ambigüedad porque les representa amenazas contra seguridad y estabilidad personal en el trabajo y prefieren tareas concretas con instrucciones especificas (Vargas Hernández; 1992). Entre los valores predominantes que se atribuyen a una cultura participativa está la tolerancia a la ambigüedad (Pérez López, Montes Peón y Vázquez Ordás, 2007).

Por lo tanto, la verbalización de interpretaciones, el parafraseo o comentarios verbalizados de los temas son parte de un esfuerzo para identificar los cuestionamientos ambiguos por todos los participantes. El nivel máximo de ambigüedad es considerado en el centro de un continuo con dos extremos en donde las variables que van de valores mínimos a valores máximos están bien definidas (Simo, Enache, Fernández, y Sallan, 20 I0).Ya no es posible apreciar el valor de la espontaneidad en los procesos individuales o en los económicos, lo que auspició el desarrollo de la organización «neurótica», empresa de acción compulsiva por tener un departamento de planeación que le asegurara que cada uno de los movimientos que se fueran dando hubiera sido cuidadosamente planeado.
En estos temas resalta el concepto de ambigüedad, en el sentido de que los individuos participantes en la organización carecen de capacidad para dirigir los procesos y para tomar decisiones con sencillez, medición y racionalidad. Esto se presenta debido a una lógica en el comportamiento natural de los individuos en la organización. El concepto ambigüedad es para expresar la compleja red de relaciones que se producen en torno y dentro de los procesos organizativos. Esta categoría conceptual se relaciona, cuando menos con cuatro características: La ambigüedad de intención, es decir, la imposibilidad de especificar procesos que satisfagan, al mismo tiempo, la consistencia de una decisión y la evidencia empírica de la acción; la ambigüedad de entendimiento, esto es, la dificultad de encontrar conexiones claras entre la acción organizada y sus consecuencias; ambigüedad de historia es la dificultad para determinar porqué paso y cuando sucedió un proceso decisorio; y por último, la ambigüedad de organización, que es la imposibilidad para identificar los patrones de conducta y participación de los actores en la toma de decisiones.

La ambigüedad desempeña un papel mucho más importante en el funcionamiento de las organizaciones del que se conoce tradicionalmente. Sin embargo la ambigüedad plantea más preguntas de las que recibe. El modelo racional de (March y Olsen; 1997: 15) explica con deficiencia la vida organizacional porque se resiste a reconocer éste amplio margen de ambigüedad que existe en las preferencias de individuos y organizaciones. March y Olsen en este mismo estudio, señalan como las reformas aditivas tienden a ser ambiguas, puestas en práctica solo a medias y finalmente olvidadas por sus promotores, para prestar atención a problemas más graves y urgentes. En todas las organizaciones puede existir ambigüedad en las decisiones, sin embargo, en algunas organizaciones de tipo gubernamental y en las instituciones educativas la ambigüedad es una constante (Del Castillo; $2001: 16$ ).

Las teorías de la ambigüedad organizativa surgen con la intención de explicar, con mayor claridad, algunos de los rasgos de irracionalidad que caracterizan a las organizaciones, y que hasta ese momento habían sido negados o tratados solo como casos especiales de incertidumbre. Las teorías de la ambigüedad se desarrollan a partir de los años 70's. Se presentan en tres formas muy relacionadas entre si:

- La forma de Cesto de Basura a cargo de Michael Cohen en 1972. 
- El Sistema Flojamente Acoplado de Kart Weick (1969-1976).

- Las Anarquías Organizadas de Michael Cohen y James March en 1974; y March y Johan Olsen en 1976 (Del Castillo; 200 I: I 5).

La toma de decisiones es un proceso ambiguo dado que es difícil determinar quienes participan en él, dónde y cuándo comenzó o qué sentido ha tomado. El acto decisorio por tanto, se describe como un proceso flojamente acoplado entre participantes, problemas, soluciones y contextos. A pesar de la ambigüedad que se describe en el proceso decisorio, este no carece de orden. Si se describe un orden en los procesos, pero es un orden distinto del que usualmente es considerado en las teorías convencionales.

La teoría de las anarquías organizadas utiliza el concepto de ambigüedad para expresar la compleja red de relaciones que se producen en torno y dentro de los procesos organizativos. La teoría de las anarquías organizadas es, una propuesta en que la decisión pierde su carácter lineal para juzgarse como un proceso complejo, de relaciones flojamente acopladas entre problemas, soluciones y participantes. Una anarquía organizada no tiene claridad ni coherencia en los objetivos que pretende, y cómo pretende lograrlo, además, quien o quienes son los responsables de tomar las decisiones, esto último denominado el constante flujo de participantes en el proceso decisorio. De tal forma que la toma de decisiones se describe como un proceso continuo porque los sucesos que siguen a los actos de decisión, como consecuencia de ellos, son generadores de nuevas realidades.

La influencia del poder dificulta el funcionamiento lineal y formal generado por la cultura organizacional, ya que dentro de la cultura se encuentran los intereses individuales, con sus propios objetivos que difieren de la misión y visión general, aunque se encuentre en el espacio organizacional. El poder aporta mayor heterogeneidad en esta área, ya que cada participante ejerce una cuota de poder y lo hace manifiesto, se organiza para ejercerlo. Lo utiliza para buscar sus propios objetivos que no siempre son compatibles con los de la organización, pero que ésta debe buscar esa compatibilidad, para reducir dicha amenaza. Al imprimirle sus aportaciones culturales ya descritas. El participante aporta además, sus intereses, problemas, individualismo que alimentan el conflicto interno y la ambigüedad, ya que la mezcla de objetivos es heterogénea y poco clara.

\section{Métodos de investigación}

Esta investigación es realizada bajo criterios metodológicos de los estudios de caso. La naturaleza del objeto de estudio permite la investigación cualitativa, considerando que el juego de las variables estudiadas solo puede determinarse observando el comportamiento y opiniones de los participantes dentro de la organización. La planeación estratégica ante la ambigüedad organizacional, nos lleva a buscar como se influyen uno en el otro; es decir, el impacto de una variable en la otra. Hay factores que influyen en el comportamiento y generan complicaciones en la organización, que no permiten el logro de los resultados de acuerdo a lo planeado.

La naturaleza controlable de los factores internos son áreas de oportunidad que se convierten en elementos estratégicos de las acciones o planes que se deben diseñar bajo la premisa de que el mejoramiento de la productividad depende de la integración de los factores (Naime Velasquez, Núñez y Rodríguez Monroy, 20 10. Ante éstas condiciones se requiere saber, cuando y porqué suceden esos comportamientos individuales y organizacionales, apostando a lo cualitativo, en una relación con lo cuantitativo al aplicar la técnica e interpretación con la escala de Likert que proyecta un proceder cuantitativo.

El sentido explorativo y descriptivo, aportan al objeto de estudio las vertientes de hacer emerger aspectos novedosos que repercuten en propuestas de posibles conclusiones de importancia en su aplicación. En este caso, la secuencia de metodología de estudio de caso tiene tres niveles:

a) Descripción del estudio de caso.

b) Procedimientos aplicarse.

c) Responder a las preguntas creadoras del objeto de estudio y sus evidencias analizadas.

La investigación se hace en una de las cuatro regiones de la universidad Autónoma de Sinaloa, que es la región centro-norte y se hace énfasis en la educación superior pública. El Universo de estudio es de I 12 profesores considerando el nivel superior de la región centro-norte y se ha aplicado un cuestionario para el $50 \%$ de estos, observando el universo alcanzable para cubrirse en su totalidad, hemos decidido por una muestra de la mitad con respecto al total, la cual, tiene una buena disposición como informante. Para conseguir la información de campo se ha aplicado un estudio con la escala de Likert. 
El diseño, estructuración y aplicación de un cuestionario con el propósito de estar en condiciones de medir las actitudes del personal en aspectos tales como: identidad institucional, grado de cumplimiento, satisfacción en el trabajo, motivación, relaciones de poder, asuntos laborales, participación de equipo, etc. Se está evaluando la opinión y experiencia en los problemas de la región centro-norte, en la perspectiva del personal administrativo y personal docente, además de realizarse una importante investigación bibliográfica. El cuestionario está formado por 43 preguntas y se aplicó con la técnica de contacto (entrevista personal) y con la estructura ya mencionada de Escala de Likert.

\section{Análisis de resultados}

\section{A) Objetivos e intereses}

Los resultados con respecto a los objetivos organizacionales y el interés individual son los siguientes:

\section{Gráfica I}

\section{Objetivos y funciones}

Siempre $\square$ Muy seguido $\square$ Raras veces

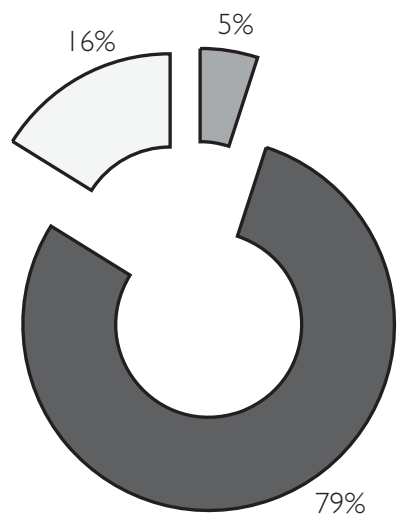

I. Tengo claros los objetivos, funciones, obligaciones y actividades relacionadas con mi trabajo

Al preguntar a los trabajadores docentes sobre la claridad de objetivos, funciones y obligaciones, el 79\% siente firmeza, ya que dice que siempre tiene claridad en ese sentido, el $16 \%$ dice que muy seguido y solo un $5 \%$ que raras veces.

2. Las autoridades vigilan el cumplimiento de los objetivos asignados al personal

El grado de atención de las autoridades sobre el cumplimiento de objetivos asignados al personal se ha respondido con un 39\% que considera que raras veces se vigila el cumplimiento, frente a una proporción casi igual que observa muy seguido la vigilancia de ello, agregando un 14\% que dice que siempre se da ese seguimiento.

Gráfica 2

\section{Cumplimiento}

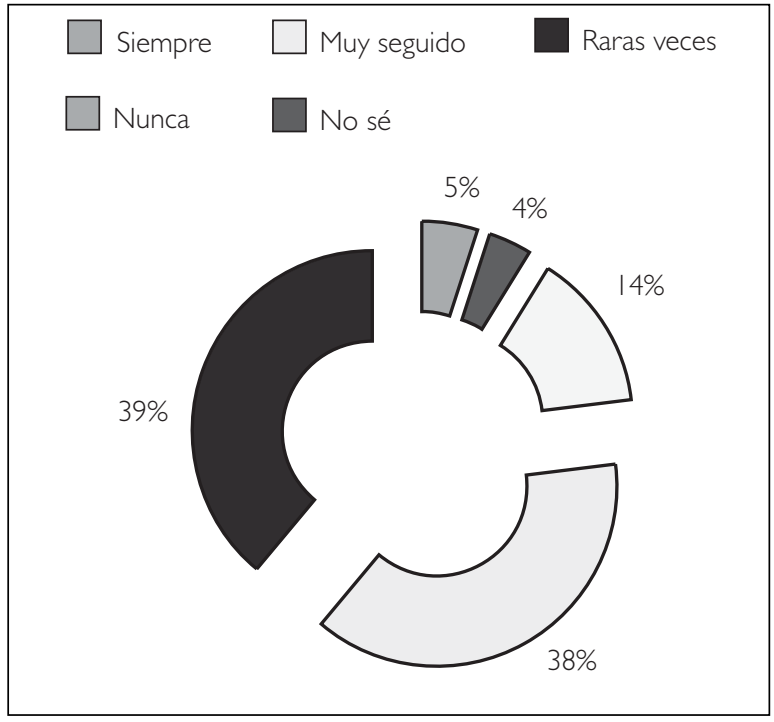

3. Cumplo con mis funciones, y demás tareas de mi responsabilidad

Gráfica 3

Funciones

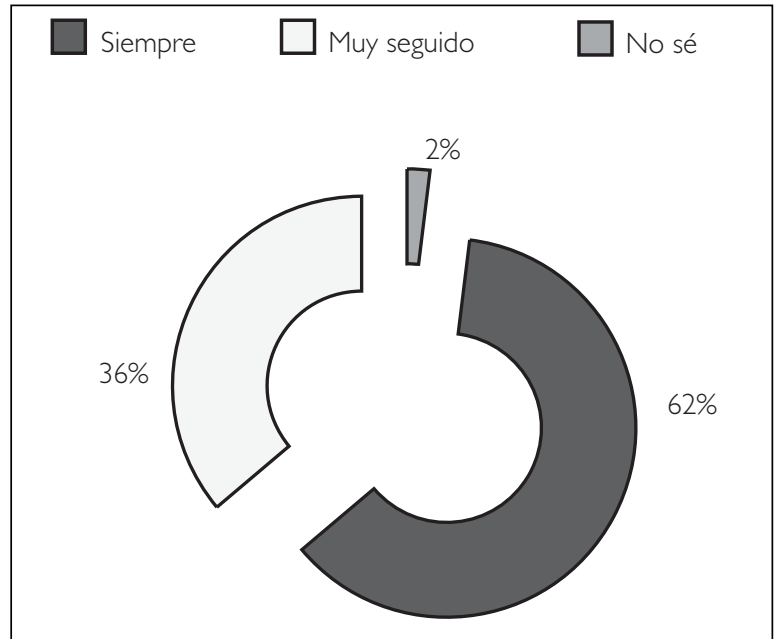

El 62 por ciento de los que respondieron señalaron que siempre cumplen con sus funciones, mientras que el 36 por ciento lo hacen muy seguido y solamente el $2 \%$ no saben si cumplen con sus funciones.

4. Mis objetivos personales se realizan en este trabajo 
El 27 por ciento aseguran que realizan sus objetivos personales en el trabajo, mientras que el 4 I por ciento sostienen que muy seguido, el 21 por ciento raras veces y un 9 por ciento que nunca.

\section{Gráfica 4}

\section{Objetivos}

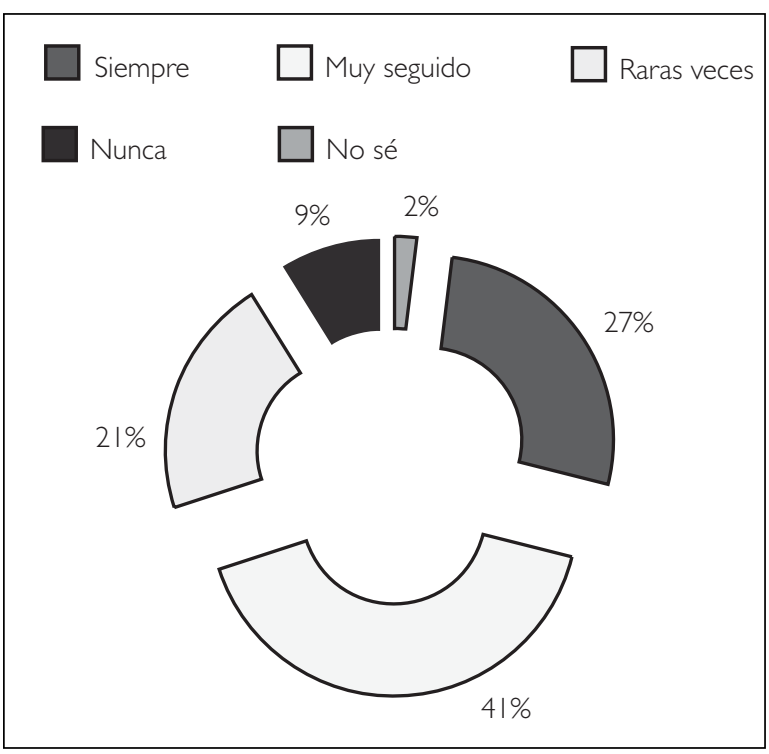

5 No se cumplen mis objetivos como trabajador y eso reduce mi rendimiento

Gráfica 5

\section{Rendimiento}

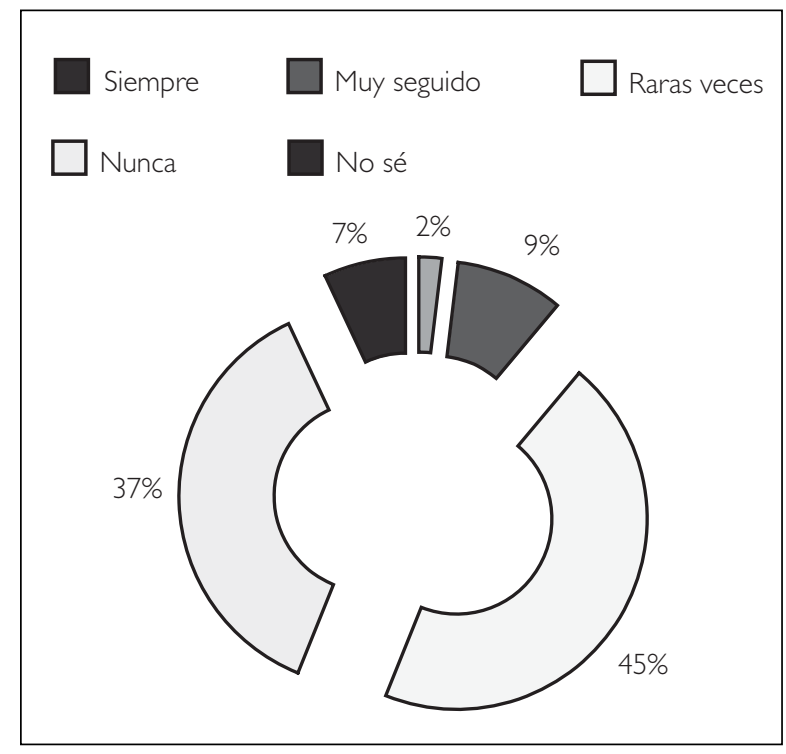

La reducción del rendimiento personal en el trabajo en un $45 \%$ raras veces tiene que ver la baja respuesta que encuentra en sus objetivos personales, mientras un 37\% considera no verse afectado en su rendimiento, al no cumplirse sus expectativas; fren- te a un $9 \%$ que dice que su funcionamiento adecuado ha sido menor debido a los bajos resultados en sus expectativas individuales.

En este terreno se presenta un grado importante de ambigüedad, debido a que se tienen las posibilidades de avanzar en este renglón y se conoce cuál es el rumbo, además se forman objetivos para concretar, pero la participación social y de equipo del personal es fría y no se encuentra estimulada para avanzar.

\section{B) Ambigüedad de objetivos y de acción}

Finalmente hay que mencionar que existe un bajo nivel de deserción del personal, situación que se enfrenta a la alta rotación del personal dada en los cambios de director generalmente cada 3 años, la cual rompe la continuidad y dificulta la marcha de los proyectos de impulso. Cuando esto sucede, se da el impulso de la ambigüedad ya que las soluciones no tienen conexión con los problemas, aunque el personal académico y administrativo se considera informado de los objetivos institucionales. Existe una gran discontinuidad de los proyectos planteados debido a la rotación del personal administrativo, generalmente cada 3 años las direcciones cambian con todo su personal. Es clara la resistencia al cambio, la cual crea más conflictos, sumándose a las eternas discusiones por la decisión de cargas académicas en estas escuelas.

6. La escuela ha ido bien y son pocas las cosas que se deben cambiar

Gráfica 6

Cambios

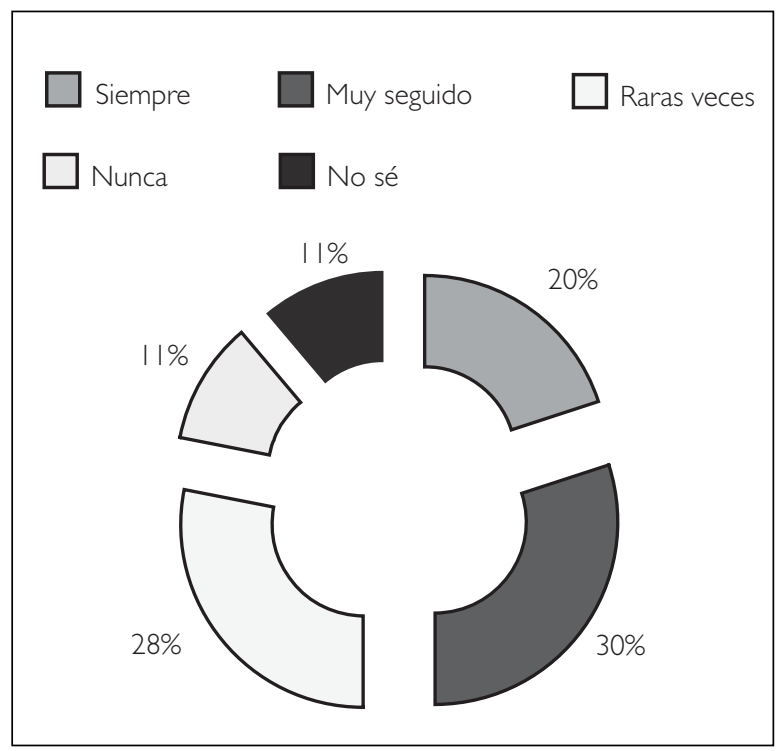


Respecto a los cambios necesarios, el 20 por ciento contestaron que le ha ido muy bien a la escuela y son pocas las cosas que se deben cambiar. El 30 por ciento argumenta que muy seguido y el 28 por ciento señalan que raras veces. Es importante señalar que un I I por ciento consideran que raras veces $y$ otro I I por ciento sostienen que nunca.

Uno de los problemas que pueden detectarse en el personal administrativo es aquel planteamiento de la teoría institucional de que las instituciones no siempre emprenden decisiones racionales, sino que muchas de estas decisiones responden a la presión ejercida por el medio. El caso de las Universidades como la UAS padece de un problema similar en la actualidad, buscando resolver sus problemas por presión del Estado. Así que dichas actividades no han nacido con convicción de sus participantes y se hace difícil adaptarlas, en algunos centros de trabajo como la región en cuestión; el cambio entonces es confuso, por que influyen variables externas que atacan a las técnicas de administración comunes.

\section{C) Poder y conflicto en la región centro-norte de la UAS. Relaciones laborales y ambigüedades}

7. El tener asegurado el trabajo influye en la problemática del incumplimiento

\section{Gráfica 7}

\section{Incumplimiento}

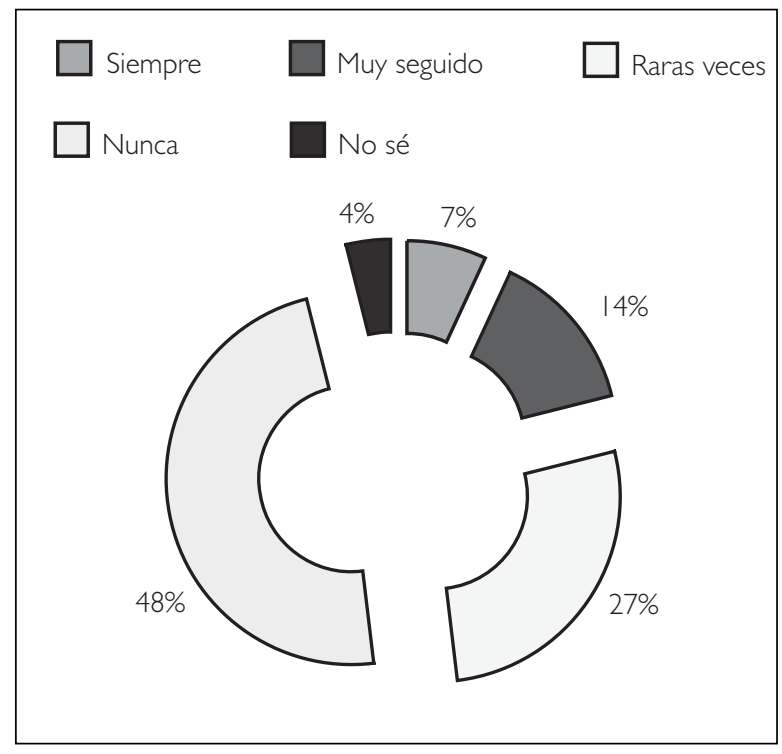

El tener asegurado el trabajo, no está relacionado con el incumplimiento dice el $48 \%$ de los trabajado- res docentes y administrativos, aunque el 27\% dice que raras veces; el I $4 \%$ opina que muy seguido si se da ese comportamiento.

8. Existe favoritismo o privilegios entre superiores y el resto de los trabajadores

Gráfica 8

Privilegios

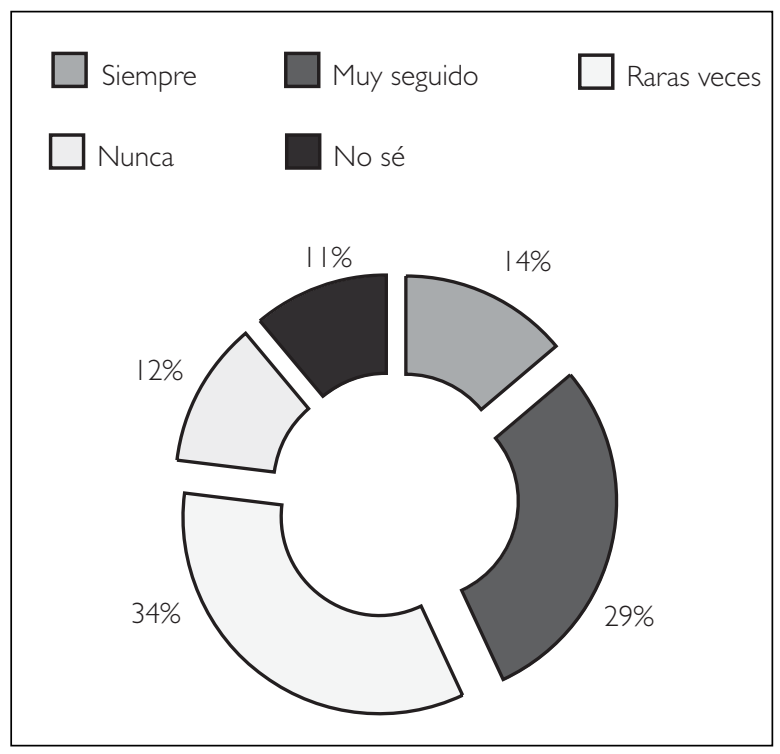

El favoritismo que protege solo a algunos se encuentra muy seguido según el $29 \%$ de los trabajadores, con un $14 \%$ que considera que siempre se presenta.

9. Es mejor tener amigos políticos que trabajar duro

\section{Gráfica 9}

Amigos políticos

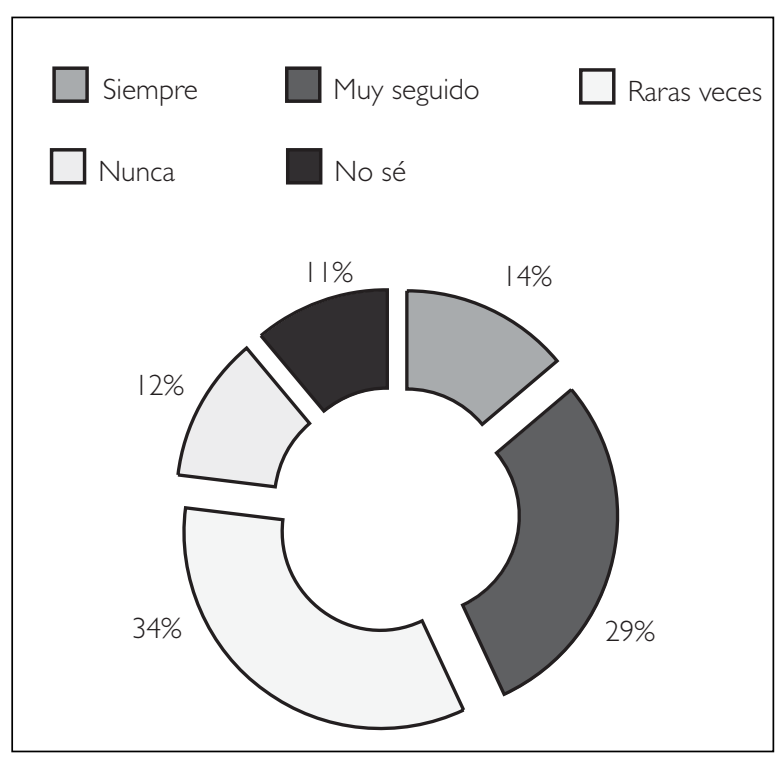


Frente a un $34 \%$ que dice que raras veces y un $12 \%$ que nunca. Un $14 \%$ opina que sirve mucho tener amigos políticos.

10. Tengo buena relación con mi jefe superior

\section{Gráfica 10}

\section{Trabajador-jefe}

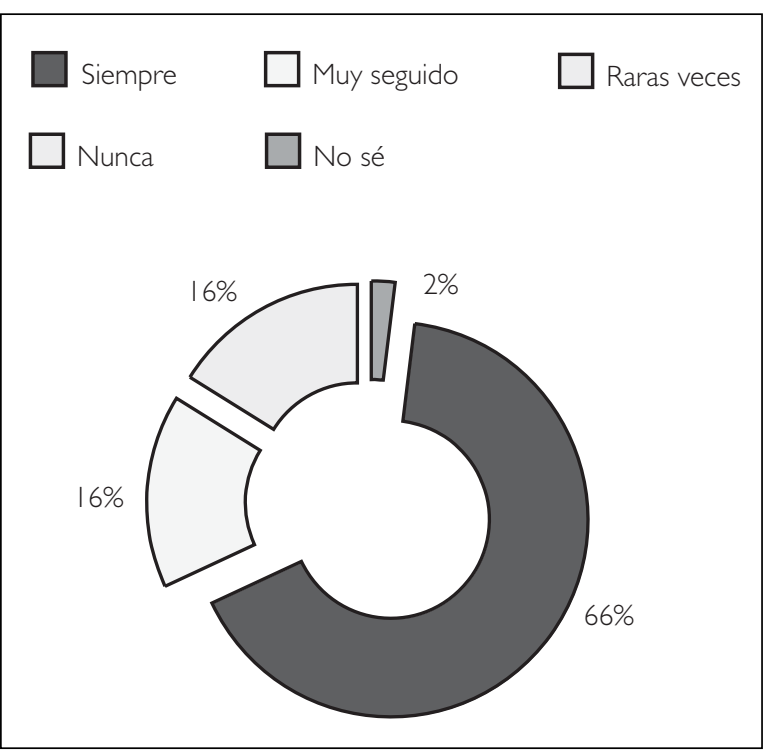

En cuanto a las relaciones con el jefe superior, el $82 \%$ presenta buenas condiciones siempre, frente a un $16 \%$ raras veces.

II. Siento compromiso con las actividades que realizo en la institución

Gráfica | |

\section{Compromiso}

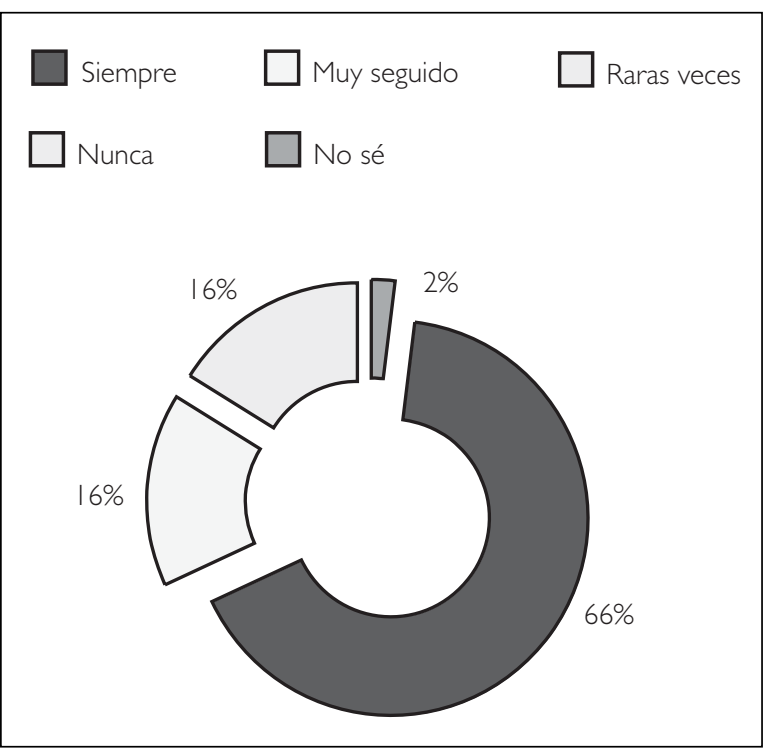

El 59 por ciento manifestaron que nunca siente que tienen compromiso con las actividades institucionales seguido por el 22 por ciento que considera que raras veces siente tener el compromiso por la institución.

12. Existen fricciones en las relaciones entre los compañeros de trabajo

Gráfica 12

Fricciones en relaciones
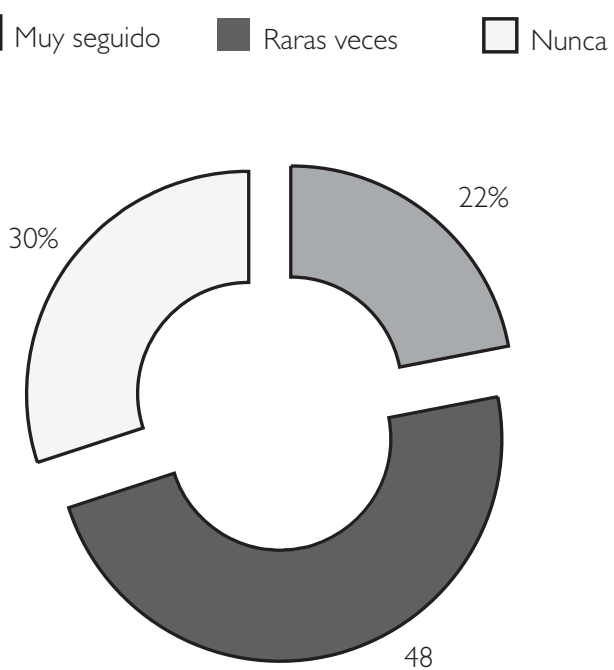

Sobre conflictos entre compañeros solo un $22 \%$ dice que muy seguido, un $48 \%$ que raras veces y un 30 que nunca.

13. Los conflictos tienen que ver con problemas de conducta de participantes

Gráfica 13

\section{Conflicto}

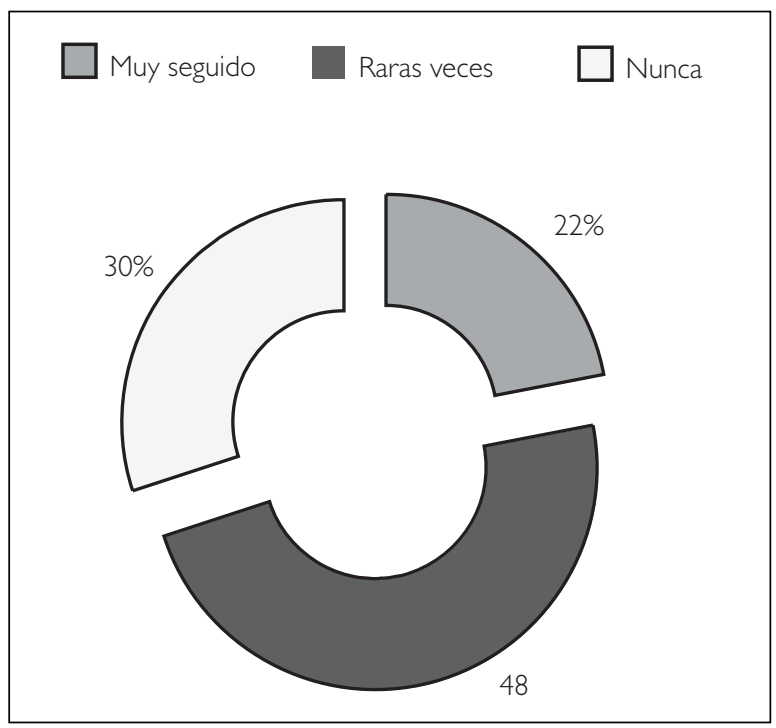


Un $26 \%$ cree que los conflictos se deben a conducta de participantes, un $45 \%$ dice que raras veces se debe a ello.

\section{D) Ambigüedad de objetivos}

La falta de estímulo en los estudiantes se incrementa con la observancia del desempleo y las escasa posibilidades que encuentran en la región, así que se tienen que implementar medidas controladoras de estas amenazas que ejercen mayor presión sobre el ya difícil camino de la educación superior pública (López López, 2004:85). Las expectativas y preferencias individuales crean una dificultad siempre cuando se alejan mucho de las acciones reguladoras organizacionales y este es un problema constante en la UAS, ante la competencia que se hacen entre los trabajadores por lograr la carga académica $\mathrm{o}$ administrativa, cada vez mas, en ese momento las relaciones de poder y el liderazgo deben actuar. Las cargas académicas deben asignarse por la comisión mixta general de admisión y promoción del personal académico y administrativo. Conforme a las reglas del contrato colectivo de trabajo, dicha comisión, siempre termina haciendo arreglos políticos creadores de conflictos. Así que se tiene que ejercer tal como está estipulada la asignación para cualquier caso.

Las labores externas, en la mayoría de los casos esta dado en la necesidad de buscar otras fuentes de ingreso, debido a los bajos salarios y bajos estímulos que la universidad ofrece a los participantes, en lo cual se incluye también a los profesores y el resto de la organización. Es el caso de la región centro-norte, aunque en muchos otros casos es por el aprovechamiento de la flexibilidad institucional hacia el cumplimiento, de la cual hacen uso, funcionarios y profesores.

14. Si la dirección implementara otras formas de control habría mayor cumplimiento

La mayoría de los proyectos y actividades planteadas por la organización central son abordados por el órgano administrativo de las escuelas, pero no se ejecuta como es debido y termina en simulación. Así que algunos de los cargos en muchas escuelas son asignados y aceptados solo para descansar de la carga académica y no hay convicción para funcionar con el papel que se le ha asignado.

En este caso los participantes en el orden administrativo que no tienen presiones en el cumplimiento de su labor, porque saben que no ocurrirá nada es- pecial con el incumplimiento, entonces no se encuentra en la necesidad de hacerlo. Sin embargo, tendrá necesidad de hacerlo, si se encuentra de por medio el salario con el que vive, ya sea porque está en riesgo su cargo, su plaza o su salario con un descuento importante. Lo mismo ocurre con los profesores para decidir actualizarse y trabajar con mayor ahínco. Tendrían la necesidad de hacerlo si observan que les puede afectar en su salario, o en la otra situación, que estén en la necesidad de aumentar sus ingresos y esa sea la solución.

\section{Gráfica 14}

\section{Cumplimiento}

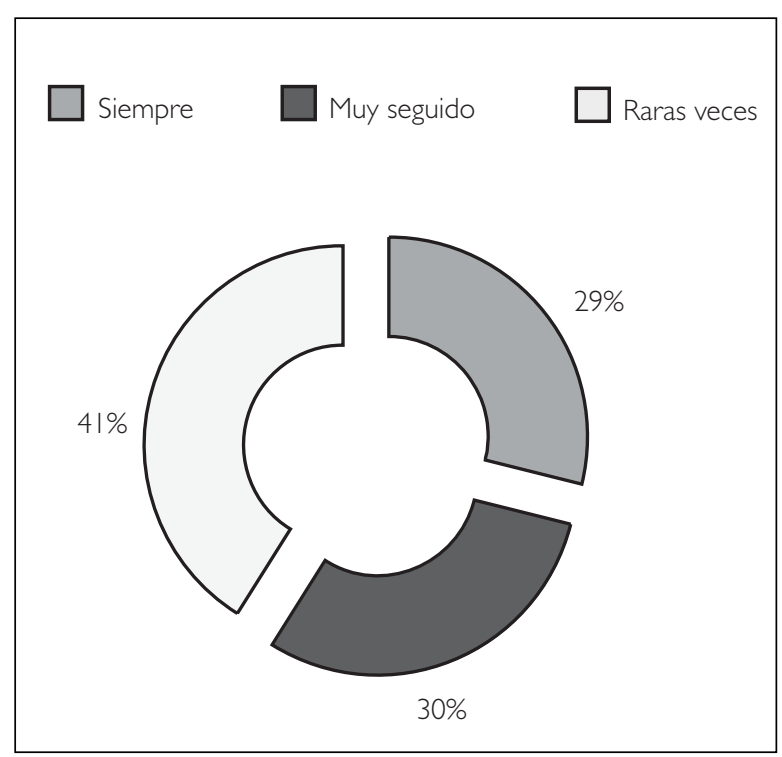

\section{E) Ambigüedad en estímulo, responsabilidad y comunicación}

Este conjunto de debilidades y fortalezas que chocan, no permiten la claridad de entendimiento y ejecución de objetivos; además cuando los proyectos se ejecutan no encuentran continuidad; a esta múltiple ambigüedad se suman el incumplimiento que se escuda de manera inconsciente en la falta de reconocimiento y falta de castigo respectivamente dada la flexibilidad de dirección marcada con el contexto político (López López, 2004:86). El asunto político provoca más desacato e incumplimiento, dado que existen diferencias entre grupos con «distintos» intereses en la lucha de poder dentro de la universidad, tales diferencias crean conflictos y retardan siempre el proceso educativo en la institución desde sus centros más pequeños hasta sus órganos mayores. Tanto que existe alto desacuerdo organizacional para decidir el rumbo de objetivos más importantes, como las plazas de T.C., jubilaciones, medidas de control, entre otros. 
15. El grado de desacuerdos personales dificulta la realización del trabajo

Gráfica 15

\section{Desacuerdos}

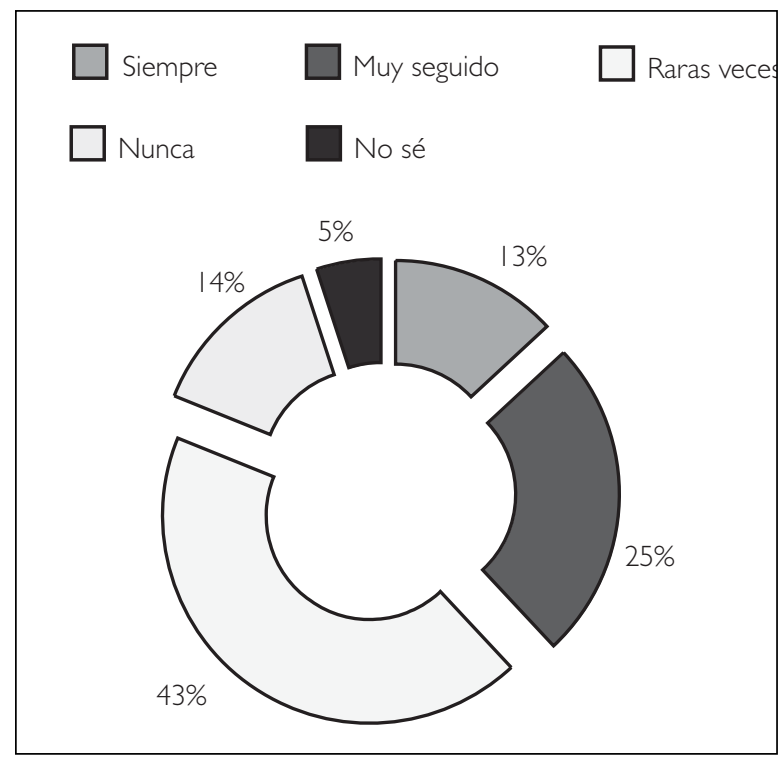

Existe un nivel democrático favorable con ideas también expresables en todos los niveles, no hay problemas de difusión de ellas, en lo cual es siempre importante el consejo universitario donde toda la institución puede escuchar y opinar; y otra de las grandes fortalezas es la existencia de un número suficiente de docentes con experiencia en su actividad y el mundo práctico de su área, sin embargo, una gran cantidad de este personal, tiene otras actividades al exterior de la universidad, justificándose en los bajos salarios que han predominado para los profesores de la educación superior.

\section{Estoy bien dispuesto para trabajar.}

Tal situación, aunque ha tenido algunos avances con los apoyos al desempeño académico, continúa una gran cantidad de rezago en este sentido, condiciones que coadyuvan a que no existan verdaderos equipos de trabajo y que el personal no se sienta identificado con la institución. Aunque para estos problemas influyen además las formas de dirección y liderazgo de quienes administran las decisiones centrales (López López, 2004:86). Casi la mitad del personal de oficio observa que existe favoritismo de tipo político en las decisiones de carácter laboral y en el trato, es decir, que existe trato preferencial de la dirección hacia la planta docente. Este problema es parte de las relaciones políticas en que se desarrolla el ambiente de decisiones laborales y con ello se provoca la tendencia al estancamiento de la actividad administrativa, por no poner en primer lugar las normas. De acuerdo a la posición de los docentes, entre las causas importantes del desinterés es la falta de compensación por mejoramiento, aunque exista el apoyo al desempeño académico, no existe en las escuelas otros elementos en este sentido, además de la inadecuada distribución de tales apoyos.

Gráfica 16

Disposición

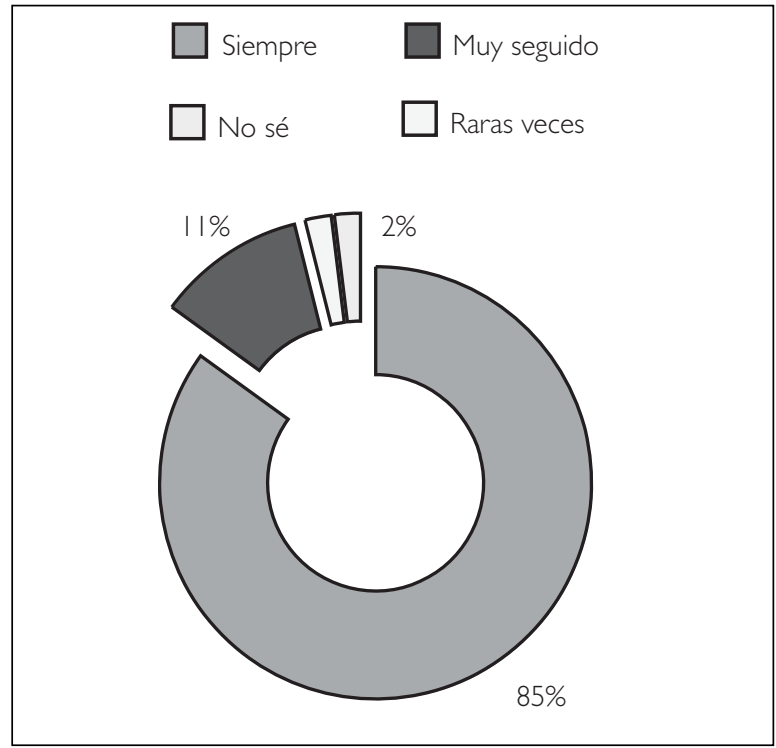

F) Conducta de los docentes en la región centro-norte de la UAS. La participación en contextos sociales

17. Establezco relaciones fácilmente con la gente

Gráfica 17

Relaciones

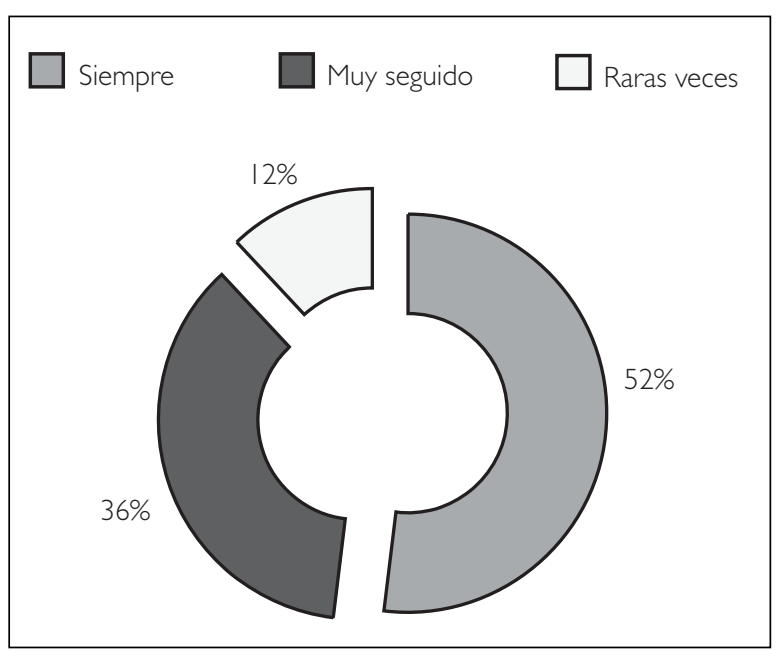


El $88 \%$ del personal se considera bueno al relacionarse con la gente, mientras el $12 \%$ no se siente así.

18. Me siento cohibido en contextos sociales

Gráfica 18

\section{Convivencia}

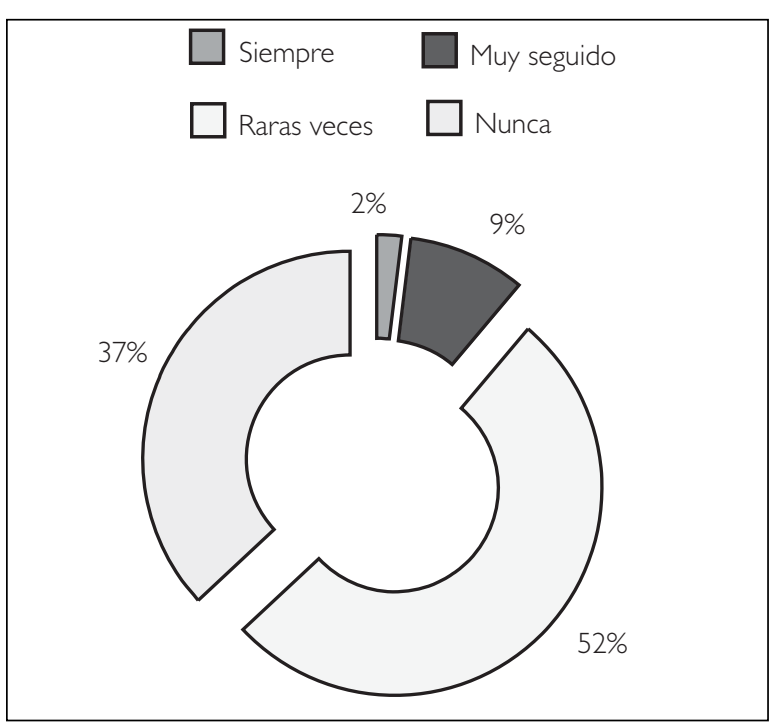

El $37 \%$ no se siente mal en contextos sociales, aunque el $52 \%$ algunas veces.

19. Se me dificulta iniciar una conversación

Gráfica 19

\section{Relaciones}

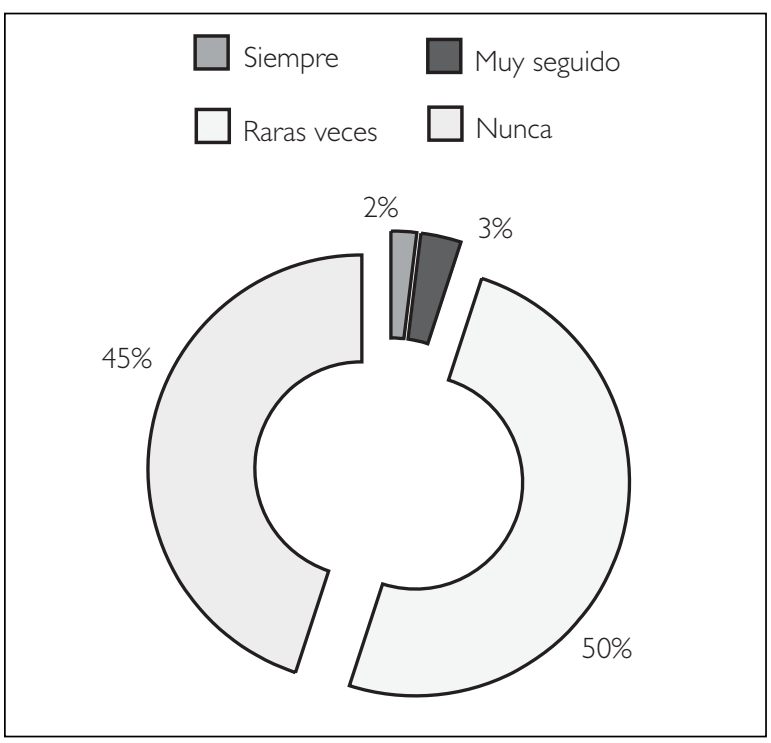

De igual manera al $45 \%$ no se le dificulta iniciar una conversación, aunque al 50\% algunas veces sufre ese problema.
20. Prefiero mantener distancia de los demás

Gráfica 20

Dificultades de equipo

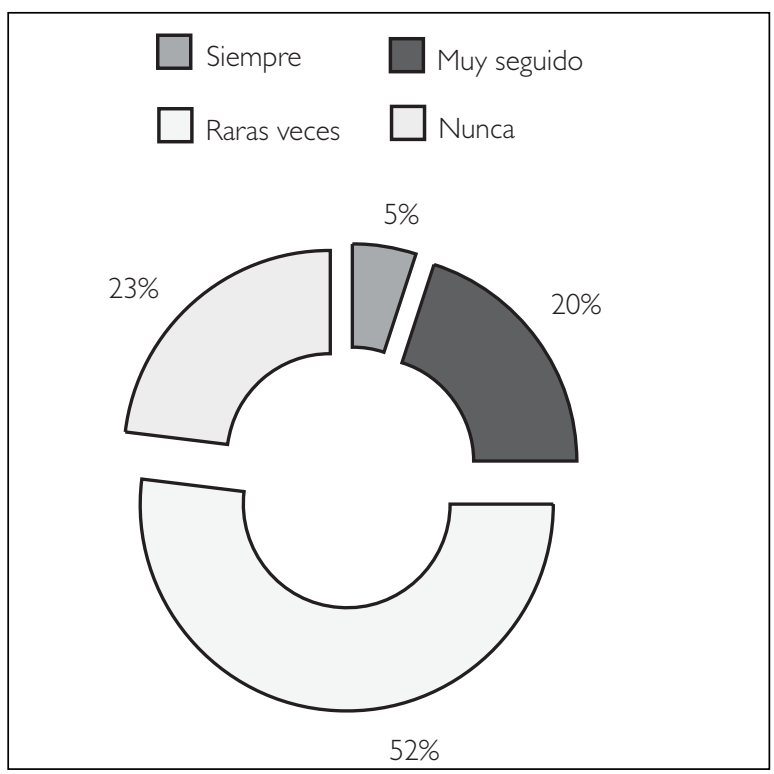

Hay un 20\% de personas que están dispuestos a mantener su distancia de los demás, mientras un 52\% raras veces y un $23 \%$ nunca.

Pero existe un gran problema de ambigüedad en este sentido, y se trata de la discontinuidad del cumplimiento de objetivos y proyectos, problema aceptado por los funcionarios como un desequilibrio de la rotación alta de personal, considerando que el personal se considera informado de los objetivos por parte de los directivos. La falta de pertenencia, identidad con la institución, escasa voluntad, personal en otras actividades, y falta de relaciones de trabajo, crean ambigüedad al no permitir el avance del personal preparado con la función docente y la práctica en su área; además, no permite avanzar al alto grado de conciencia de los problemas y el reconocimiento por parte de los trabajadores en las perspectivas positivas de las reformas.

21. En contextos sociales.

\section{Conclusiones}

Las estrategias pueden estar consideradas en un aceptable grado de racionalidad, considerando el acoplamiento de los factores culturales ya planteados y determinados en un orden de objetivos adecuado, pero los recursos son limitados; la información como otra parte de los recursos también es 
limitada y se pierde racionalidad en las estrategias, haciéndola más compleja. Además, la lucha por los recursos, por parte de las áreas de actividad; las alianzas y movimientos del micro poder como plantea Mintzberg, como el juego del presupuesto, hacen más compleja la búsqueda de compatibilidad entre estrategias, recursos, decisiones, objetivos, entre otros. La cooperación actual es competitiva y no solidaria; es de conseguir y no de dar; los rivales pueden estar en la alianza; no están los factores tradicionales de la armonía y la cooperación, colaboración y solidaridad; más bien se encuentra vinculada a los recursos con que se relaciona y los que quiere conseguir en la llamada cultura material. Con la necesidad de permanecer y sobresalir o por lo menos no ser dañado, por ese tipo de orden oligopólico, donde las estrategias de unos pueden estar dirigidas contra otros.

Gráfica 21

Dificultades de comunicación

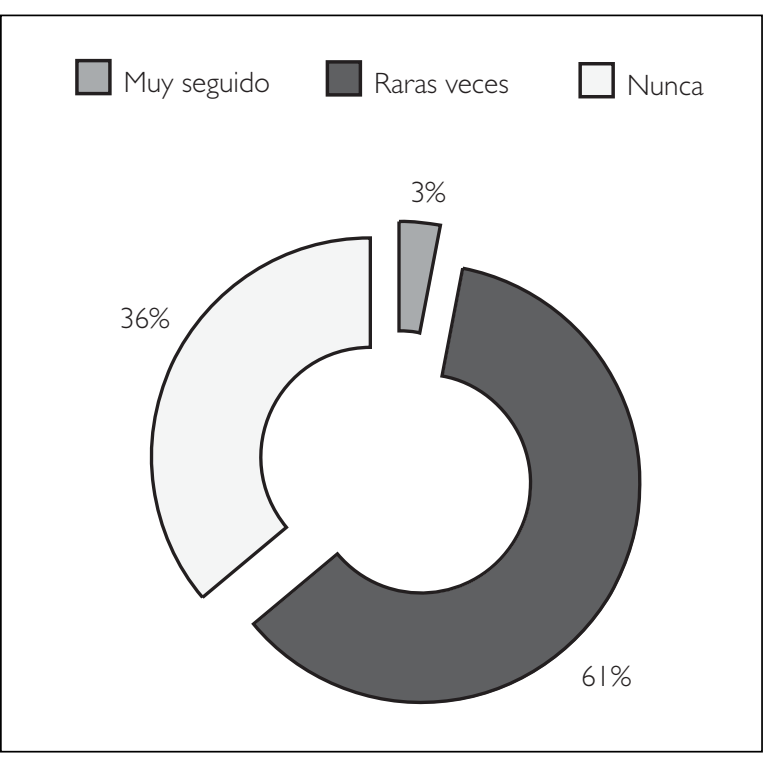

La capacidad para identificar y reproducir los componentes del sistema de RRHH que subyacen como ventaja competitiva y las circunstancias bajo las que funcionan implica superar la ambigüedad causal, la complejidad social y las condiciones históricas únicas como «mecanismos de aislamiento» (Sanchis Palacio, y Campos Climent, 20 I0). La ambigüedad de acción y de intención en los recursos ha resuelto mayormente infraestructura y tecnología, aunque es más limitado el pago de recurso humano. Las limitaciones en sueldos, generan dificultades para proveer de profesores investigadores de tiempo completo y las unidades académicas resuelven con una mayor parte de personal de asignatura que no está disponible para las otras tareas relevantes de la organización, que ahora son una necesidad ante las exigencias de acreditación. El 80\% del personal se encuentra en esta situación de menor compromiso, con ello el impulso en tecnologías e infraestructura se subutiliza.

Uno de los problemas que pueden detectarse en el personal administrativo y docente, es aquel planteamiento de la teoría institucional que dice que las instituciones no siempre emprenden decisiones racionales, sino que muchas de estas decisiones responden a la presión ejercida por el medio. El caso de las universidades como la UAS padece de un problema similar en la actualidad, buscando resolver sus problemas por presión del Estado. Así que dichas decisiones no han nacido con convicción de sus participantes y se hace difícil adaptarlas. En algunos centros de trabajo como los de la región centro norte, aquí tratada; el cambio es confuso, porque influyen variables externas que atacan a las técnicas de administración comunes. Ante las condiciones planteadas no se puede atender la demanda creciente que se presenta por los programas académicos, dadas las limitaciones en recurso humano, de tal manera que, el impulso de las nuevas opciones en otras instituciones se hace más relevante. Dentro de los objetivos centrales de la Universidad resalta la identidad con la sociedad e históricamente la sociedad con dificultades económicas, pero además, cumplir las tareas de educación al nivel que la sociedad requiere, de calidad, donde el impulso a la investigación y el posgrado tienen que aparecer en primer plano. Estos objetivos se confrontan con un rezago en recurso humano disponible por las causas ya descritas. La racionalidad simoniana (Simon, 1947) entonces, se encuentra en un ambiente de limitación que crece, con la combinación de los otros elementos organizacionales que participan, como las presiones del macropoder y también el micropoder, que, aunque han tenido reformas recientes, está presentando nuevas inquietudes.

Las reformas son importantes en el orden académico, administrativo, en lo político, en la investigación, lo que ha permitido avanzar a estándares no considerados hacía unos años. En estos momentos, los estudiantes, encuentran mejores expectativas al iniciar y al terminar su estudio; además, los profesores se encuentran en procesos de capacitación y mejoramiento de su perfil, aunque se conservan las dificultades de incorporación al trabajo colegiado, entre otras causas la de las escazas posibilidades de incorporación de nuevos tiempos completos. Se tiene disposición en el personal, que parece suficiente, sin embargo presenta ambigüedad, dada la baja participación en equipo y las ocupaciones diversas que el personal tiene 
en otras organizaciones afuera de la Universidad, incluso, no siempre educativas, ante la carencia de motivación que los promueva con mayor estabilidad, como puede ser el tiempo completo, medio tiempo, becas; aunque ellos sienten motivación para la parte que les corresponde cumplir. Lo que pudieran revertir algo de este comportamiento es el programa de estímulos al desempeño académico. Pero tal programa, no alcanza las formas tayloristas del control que se requiere, pues no corresponde en los términos de medir el mérito y el no mérito, ya que se distribuye de una forma más discrecional.

Cuando el personal declara tener claridad en los objetivos parece que tenemos respuestas, aunque hay que observar lo anterior expuesto para determinar, que al cumplir con sus clases solamente, sin participar en equipo y las demás tareas ya descritas, que muchas de ellas no le corresponden por ser solo de asignatura, entonces sus objetivos e intereses personales le mueven las tereas de la organización y la ambigüedad de intención y de acción toma caminos difíciles, bajo las condiciones del interés individual smithiano.

Una de las tareas importantes es incorporar en la los programas de desarrollo y formación profesional como una de las competencias específicas que MarinGarcia, García-Sabater y Canós-Darós (2010) proponen para la formación de un ingeniero de organización es la capacidad para decidir en situaciones que son ambiguas o inciertas porque hay diferentes criterios en juego. Hay respuesta en las peticiones y necesidades laborales, que hasta hace unos años no se cumplía. Actualmente se avanza en estabilidad laboral y mejores condiciones de trato, condición alimentado por el saneamiento político del nuevo orden, planteado en la ley orgánica, en la determinación sobre gobierno y autoridades universitarias.

\section{Bibliografía}

ALBORS-GARRIGÓS, J., DEL VAL SEGARRA, M. Y RINCÓN-DÍAZ, C.A. (20I0). «Los Institutos Tecnológicos en el Sistema de Innovación Regional Valenciano. Propuesta de un modelo contingente de estrategia y desempeño», Dirección y Organización, Núm. 42, Diciembre 2010 .

CHIVITE, SY MONROY, C. R. (2009) «Análisis de los diez años de gobierno corporativo en España y cumplimiento del Código Unificado o Código Conthe», Dirección y Organización, Núm. 37, Febrero 2009

COHEN, M.D., J. G. MARCH, J.P. OLSEN (1974) Leadership \& Ambiguity:The American College President, New York, Mc Graw Hill.
CUENCA, LL., BOZA, A., ALARCÓN, F, Y LARIO, F.C. (2009). «Metodología para la identificación de inputs y outputs de procesos de negocio en un entorno colaborativo», Dirección y Organización, Núm. 37, Febrero 2009

DEL CASTILLO, A., (200I). Ambigüedad y decisión: una revisión a la teoría de las anarquías organizadas, documento de trabajo del CIDE, México, DF. p. 6.

GALLARDO,V., A., Y SÁNCHEZ M., A., ( 1995). La turbulencia y la planeación en las organizaciones, en revista, Gestión y estrategia. DCSH UAM. Dep. Administración. Sustraído el 13 de Febrero de 2008. prodeco.xoc. uam.mx

LÓPEZ LÓPEZ., .., J., (2004). La función administrativa dentro del sistema flojamente acoplado. El caso de la Universidad Autónoma de Sinaloa. Tesis de Maestría en Administración de Negocios en la Universidad de Occidente, Los Mochis, Sinaloa. p.p. 80-87.

MARCH, J., G., Y OLSEN, J., P. ( I 997). El redescubrimiento de las instituciones, La base organizativa de la política, Editorial Fondo de Cultura Económica, México. p.p. 10-20.

MARCH, J., G.,Y OLSEN, J., P. (1976). Ambiguity and choice in organizations. Bergen: Universitetsforlaget, 1976.

MARIN-GARCIA, J.A., GARCÍA-SABATER, J. P.Y CANÓSDARÓS, L. (2010) «La Ingeniería de Organización ante el diseño de los nuevos títulos europeos», Dirección y Organización, Núm. 4I, Julio 2010.

NAIME VELASQUEZ, Y., NÚÑEZ, M., Y RODRÍGUEZ MONROY, C. (20I0). «Aplicación de la técnica AHP para evaluar el efecto de los valores organizacionales en la productividad», Dirección y Organización, Núm. 4l, Julio 2010.

PÉREZ LÓPEZ, S., MONTES PEÓN, J. M.YVÁZQUEZ ORDÁS, C. J. (2007). «Influencia de la Cultura Organizativa sobre el Aprendizaje: Un Análisis Empírico», Dirección y Organización, 34,Junio, 2007

SANCHIS PALACIO, J. R.Y CAMPOS CLIMENT,V. (20 I0). «Las prácticas de RR. HH. de alto rendimiento y su relación con el comportamiento estratégico y organizativo de la empresa. El caso de las entidades de crédito españolas», Dirección y Organización, Núm. 40, Abril 2010.

SIMO, P., ENACHE, M., FERNÁNDEZ, VY SALLAN, J. M. (20I0) «Perfiles de carrera profesional y comportamiento organizativo: Análisis de condiciones necesarias y suficientes», Dirección y Organización, Núm. 4I, Julio 2010.

UAS (2002) Taller de Planeación Estratégica. Universidad Autónoma de Sinaloa Ed. UAS, Culiacán Sin., Feb- Abril del 2002. pp. I-6. 
SIMON, H., A., ( 1947). El comportamiento administrativo, Aguilar, Buenos Aires, 1988. . Sustraído el 13 de Febrero de 2008 http://es.Wikipedia.org/w/index.ph

VARGAS HERNÁNDEZ, J. G. ( I 992). La Culturocracia organizacional en México, sustraído el 20 de Agosto de 2009. http://google.com/booksculturocracia.
VARGAS, HERNÁNDEZ, J., G., (2009). La Educación del futuro, el futuro de la educación en México, en Gaceta, UAS, Julio- Agosto, p. p, I I-22.

WEICK, K. ( 1976) «Educational organizations loosely coupled systems» Administrative Science Quarterlu, 21 (1976), I-9 (part). 